\title{
Microscopic Findings Reference Identifier
}

National Cancer Institute

\section{Source}

National Cancer Institute. Microscopic Findings Reference Identifier. NCI Thesaurus. Code C117575.

A character or string used to name, or characterize a microscopic findings reference. 